TAPROBANICA, ISSN 1800-427X. April, 2012. Vol. 04, No. 01: pp. 5-11.

(C) Taprobanica Private Limited, Jl. Kuricang 18 Gd.9 No.47, Ciputat 15412, Tangerang, Indonesia.

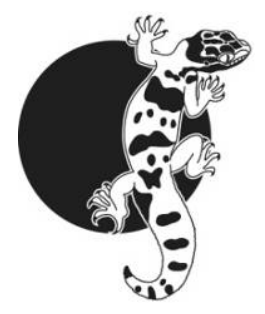

\title{
Physoschistura tuivaiensis, A NEW SPECIES OF LOACH (TELEOSTEI: NEMACHEILIDAE) FROM THE TUIVAI RIVER, MANIPUR, INDIA
}

Yumnam Lokeshwor ${ }^{1,3}$, Waikhom Vishwanath ${ }^{1,4}$ and Keisham Shanta ${ }^{2}$

\footnotetext{
${ }^{1}$ Department of Life Sciences, Manipur University, Canchipur, Imphal 795 003, Manipur, India

${ }^{2}$ Department of Zoology, L. Sanoi College, Nambol, Manipur, India

Emails: ${ }^{3}$ lokeyum24@gmail.com, ${ }^{4}$ wvnath@gmail.com
}

\begin{abstract}
:
Physoschistura tuivaiensis is described from Likhailok on the Tuivai River, a tributary of the Brahmaputra River in southern Manipur, India. It is distinguished from congeneric species except $P$. shanensis and $P$. yunnaniloides by having a complete lateral line. It can be distinguished from those two species by the presence of 12-14 dark olivaceous blotches on the flank, and 15-17 dark olivaceous saddles on the back, more branched caudal fin rays, and $4+8$ pores in the infraorbital canal. Examination of the holotype of Physoschistura elongata shows lip morphology different from Physoschistura, and the species is referred tentatively to Schistura.
\end{abstract}

Key words: Anatomy, freshwater, morphology, taxonomy, Brahmaputra River.

\section{Introduction}

The nemacheilid genus Physoschistura Bănărescu \& Nalbant, 1982 comprises species of small adult size, shorter than $60 \mathrm{~mm}$ standard length. The genus is characterized by the unique mouth shape, with a strongly arched mouth, its width 1.5-2.0 times that of length, and the lower lip presenting a median interruption separating two lateral, broadly triangular pads with deep, nearly parallel furrows (Chen et al., 2011; Kottelat, 1990). The two halves of the air-bladder capsule are joined and coalescent on their inner face, the posterior chamber of the air bladder well developed, open posteriorly, more or less conical, and in direct contact with the capsule (Singh et al. 1982; Bănărescu \& Nalbant, 1995), but this condition is also present in Schistura similis Kottelat, 1990 and Yunnanilus brevis (Boulenger, 1893) (Kottelat, 1990). Seven species of Physoschistura are currently treated as valid, viz., P. brunneana (Annandale, 1918), P. elongata Sen \& Nalbant, 1982, P. pseudobrunneana Kottelat, 1990, P. raoe (Hora, 1929), P. rivulicola (Hora, 1929), $P$. shanensis (Hora, 1929) and $P$. yunnaniloides Chen, Kottelat \& Neely, 2011, with a combined geographical distribution encompassing both lentic and lotic habitats in the upper parts of the Brahmaputra, Irrawaddy, Salween, and Mekong River drainages (Kottelat, 1990; Chen et al., 2011). The Tuivai River, a tributary of the Brahmaputra, 
flows from east to west in between Manipur and Myanmar and then between Manipur and Mizoram, India. The river then flows northward and joins the Barak River at Tipaimukh. The ichthyofaunal diversity of the Tuivai River is poorly explored. Vishwanath \& Shanta (2004) described Badis tuivaiei from the Tuivai River basin. Examination of specimens collected by K. Shanta Devi in MUMF and from our own collection revealed an unnamed nemacheilid species which conforms to the generic characters mentioned above and the objective of the present paper is to provide formal description of this species.

\section{Materials and Methods}

Measurements were made point to point with dial callipers on the left side of the body and recorded to nearest $0.1 \mathrm{~mm}$. Measurements follow Kottelat (1990). Subunits of the head are presented as proportions of head length. Head length itself and measurements of body parts are given as proportions of standard length (SL). Illustrations were made on the images captured by using a Leica DFC 425 fitted on a Leica stereo-zoom microscope S8APO. The specimens are deposited in the Manipur University Museum of Fishes (MUMF), Imphal, Manipur, India. Examined specimens for comparison belong to the collections of Zoological Survey of India (ZSI), Kolkata, and Zoological Survey of India Eastern Research Station (ZSI/ ERS), Shillong.

\section{Results}

\section{Physoschistura tuivaiensis, new species}

(Fig. 1, Table 1)

Holotype: MUMF 5089: adult female $(46.0 \mathrm{~mm}$ SL); Tuivai River at Likhailok $\left(24^{\circ} 04^{\prime} 41^{\prime \prime} \mathrm{N}, 93^{\circ}\right.$ 33' 67" E, altitude $635 \mathrm{~m}$ a.s.1.), Churchandpur district, Manipur, India (Brahmaputra basin); Y. Lokeshwor and party, 20 December 2011.

Paratypes (7 specimens): MUMF 5082, adult female (45.2 mm SL); MUMF 5083, adult female (44.7 mm SL); MUMF 5084, adult female (42.6 mm SL); MUMF 5085, adult male (40.9 mm SL); MUMF 5086, adult male (40.9 mm SL); MUMF 5087 (Fig. 1B), adult male (40.8 mm SL); MUMF 5088, adult male (37.4 mm SL); Tuivai River, locality not given $\left(24^{\circ} 07^{\prime} 17^{\prime \prime} \mathrm{N}, 93^{\circ} 19^{\prime} 41^{\prime \prime} \mathrm{E}\right.$, altitude $481 \mathrm{~m}$ a.s.1.), Churchandpur district, Manipur, India (Brahmaputra basin); K. Shanta Devi, 5 May 2004.
Diagnosis: Physoschistura tuivaiensis is distinguished from all other known species of Physoschistura except $P$. shanensis and $P$. yunnaniloides by having a complete lateral line. It is easily distinguishable from $P$. shanensis by having 12-14 (vs. 8) dark olivaceous blotches on flank; presence (vs. absence) of 15-17 dark olivaceous saddles on back; $8^{1 / 2}$ (vs. $9^{1 / 2}$ ) branched dorsal fin rays, 10 (vs. 12) pectoral fin rays, and $8+7$ (vs. $8+8$ ) branched caudal fin rays; $4+8$ (vs. $4+11$ ) pores in infraorbital canal, and 9 (vs. 6) supraorbital canal. It also differs from $P$. yunnaniloides in having 12-14 blotches (vs. 18-20 bars) on flank, presence (vs. absence) of free posterior air chamber and $8+7$ (vs. $8+8$ ) branched caudal fin rays. Further it is easily recognizable in having the following combination of character states: 4 simple and $8 \frac{1}{2}$ branched rays in dorsal fin; axillary pelvic lobe well formed; suborbital flaps in males; $4+8$ pores in infraorbital canal; and interrupted black basicaudal bar with an upper small oblique bar and a lower vertically elongated bar.

Etymology: The specific epithet derives from the type locality of the species, the Tuivai River.

Description: Body moderately elongate, dorsal profile slightly arched, depth gently increasing from tip of snout to dorsal fin base, thereafter sloping evenly up to caudal fin base. Body slightly compressed anteriorly and more compressed posteriorly. Ventral profile straight throughout. Head depressed. Snout pointed, about twice length of eye diameter.

Dorsal fin with four simple and $81 / 2$ branched rays $(\mathrm{N}=8)$, articulated almost equidistantly between tip of snout and caudal base, slightly in advance of pelvic fin origin. Dorsal fin height almost equal to head width at cheek. Distal margin of dorsal fin straight. Anal fin with three simple and 51/2 branched rays $(\mathrm{N}=8)$, reaching caudal fin origin when adpressed. Pectoral fin with one simple and nine branched rays $(\mathrm{N}=8)$, articulated horizontally to vertical axis of the body, almost equal to dorsal head length, reaching about two-thirds distance to pelvic fin origin. Pelvic fin with one simple and seven branched rays $(\mathrm{N}=8)$; origin vertical below second branched dorsal fin ray, reaching to or beyond vent but not touching anal fin origin when adpressed, leaving a gap as wide as eye diameter. Axillary pelvic fin lobe well formed. Caudal fin with $8+7$ branched rays $(\mathrm{N}=8)$, forked, lobes equal in length. Caudal peduncle 1.1-1.4 times longer 
than deep, with low dorsal and ventral adipose crests on posterior half.

Body covered with slightly embedded minute scales. Ventral surface of prepelvic area devoid of scales. Lateral line complete, with $75(\mathrm{~N}=2), 77$ $(\mathrm{N}=1), 80 \quad(\mathrm{~N}=3), 81 \quad(\mathrm{~N}=1), 82 \quad(\mathrm{~N}=1)$ pores. Cephalic lateral line system with nine supraorbital, $4+8$ infraorbital, nine preoperculo-mandibular and three supratemporal pores. Unculi present on lips, barbels, throat, snout and pectoral fin rays.

Anterior nostril in front of low flap-like tube. Mouth strongly arched, about 1.5-2.2 times wider than long; lips quite thin, upper lip with small median incision and numerous shallow lateral furrows. Lower lip with wide median interruption, forming two lateral broadly triangular pads with furrows on either side (Fig. 2). Processus dentiformis present, not prominent. Shallow median notch present in lower jaw. Free posterior chamber of air bladder well formed, not encapsulated, slightly oval (Fig. 3). Inner rostral barbel reaching to point vertical of posterior margin of nostril; outer one reaching to vertical of posterior margin of orbit. Maxillary barbel reaching beyond vertical of posterior margin of orbit. Intestine without loop but with L-bend little behind stomach (Fig. 4).

Sexual dimorphism: Prominent spoon-shaped suborbital flap present in males (Fig. 5).
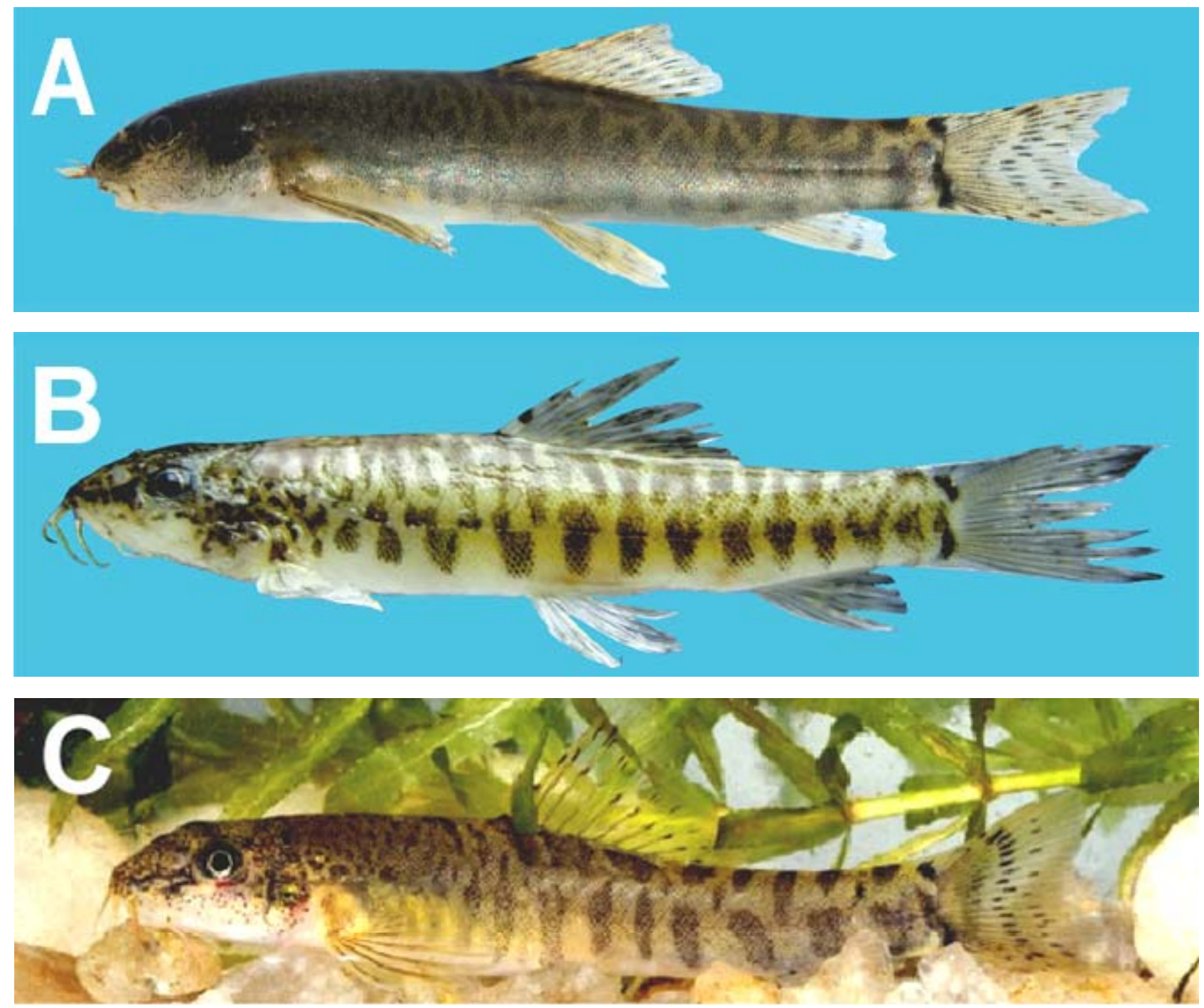

Figure 1: Physoschistura tuivaiensis: (A) holotype MUMF 5089, female (46.0 mm SL); (B) paratype MUMF 5087, male (40.8 mm SL); (C) MUMF 5090 in life (43.7 mm SL). 
Table: 1 Morphometric data of holotype and seven paratypes of Physoschistura tuivaiensis in mm except for standard length.

\begin{tabular}{|c|c|c|c|c|}
\hline & Holotype & $\begin{array}{c}\text { Range } \\
\text { (holotype and } \\
\text { paratypes) }\end{array}$ & Mean & SD \\
\hline Standard length (mm) & 46.0 & $37.4-46.0$ & & \\
\hline \multicolumn{5}{|l|}{$\%$ SL } \\
\hline Body depth & 19.6 & $17.2-20.1$ & 18.4 & 1.1 \\
\hline Head depth at nape & 16.1 & $13.9-16.1$ & 14.5 & 0.7 \\
\hline Head depth at eye & 13.0 & $11.4-13.6$ & 12.1 & 0.8 \\
\hline Dorsal head length & 21.5 & $21.5-24.5$ & 23.6 & 1.0 \\
\hline Lateral head length & 24.1 & $24.1-27.3$ & 26.0 & 0.9 \\
\hline Caudal peduncle length & 15.4 & $12.7-16.4$ & 14.4 & 1.3 \\
\hline Caudal peduncle height & 11.3 & $10.5-11.3$ & 11.0 & 0.2 \\
\hline Predorsal length & 49.1 & $49.3-52.8$ & 50.5 & 1.4 \\
\hline Prepelvic length & 52.2 & $51.9-55.3$ & 53.4 & 1.2 \\
\hline Preanus length & 73.7 & $69.0-73.7$ & 71.2 & 1.7 \\
\hline Preanal length & 78.7 & $76.7-80.3$ & 78.9 & 1.1 \\
\hline Dorsal fin height & 17.4 & $14.7-17.4$ & 15.9 & 1.0 \\
\hline Anal fin depth & 18.5 & $15.6-20.2$ & 18.3 & 1.5 \\
\hline Pectoral fin length & 22.0 & $21.1-24.6$ & 23.0 & 1.1 \\
\hline Pelvic fin length & 19.3 & $18.3-20.9$ & 19.3 & 1.0 \\
\hline Maximum head width & 16.1 & $14.9-16.5$ & 15.7 & 0.6 \\
\hline Head width at nares & 10.2 & $9.8-10.4$ & 10.2 & 0.2 \\
\hline Body width at dorsal fin origin & 15.7 & $12.2-15.7$ & 13.5 & 1.1 \\
\hline Body width at anal fin origin & 9.3 & $6.9-9.3$ & 8.0 & 0.8 \\
\hline \multicolumn{5}{|l|}{ \% Head length } \\
\hline Snout length & 45.5 & $43.4-49.7$ & 46.8 & 2.0 \\
\hline Interorbital distance & 27.3 & $27.3-32.7$ & 31.2 & 2.0 \\
\hline Eye diameter & 23.2 & $19.0-25.0$ & 22.5 & 2.0 \\
\hline Mouth gape width & 33.3 & $27.1-33.3$ & 29.0 & 3.0 \\
\hline Maximum head width & 74.7 & $60.8-74.7$ & 66.6 & 4.0 \\
\hline Head width at nares & 47.5 & $41.0-47.5$ & 43.4 & 2.0 \\
\hline
\end{tabular}

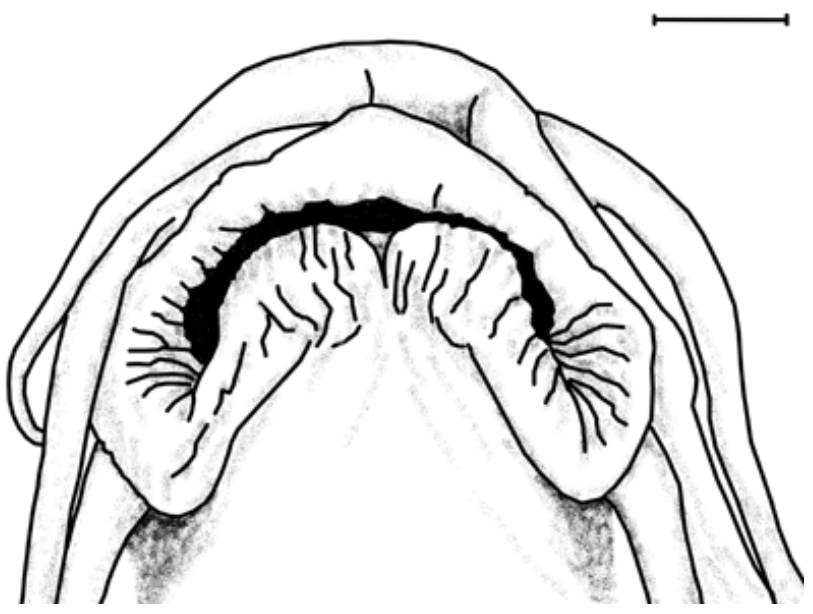

Figure 2: Ventral view of mouth of Physoschistura tuivaiensis. Scale bar $=1.0 \mathrm{~mm}$.

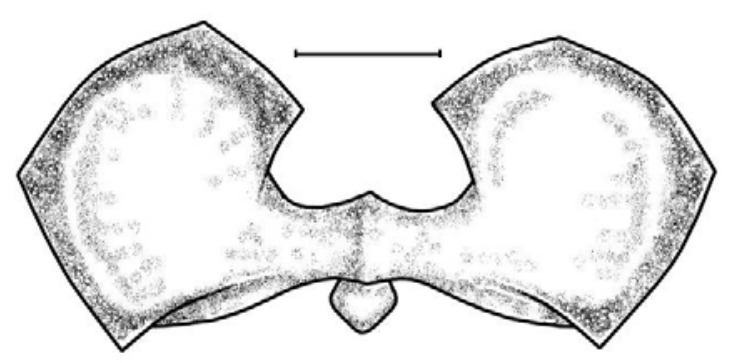

Figure 3: Ventral view of swim bladder of Physoschistura tuivaiensis, showing free posterior chambers. Scale bar $=1.0 \mathrm{~mm}$. 


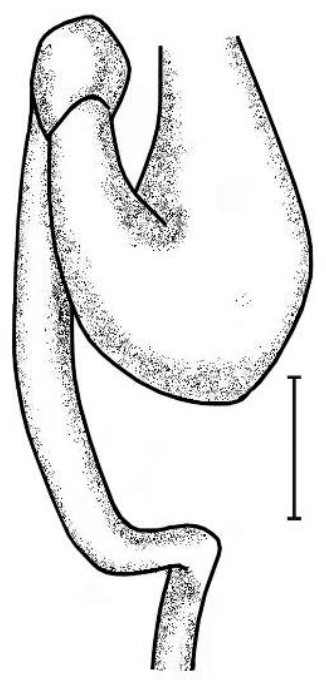

Figure 4: Ventral view of intestine of Physoschistura tuivaiensis, showing coiling pattern. Scale bar $=1.0 \mathrm{~mm}$.

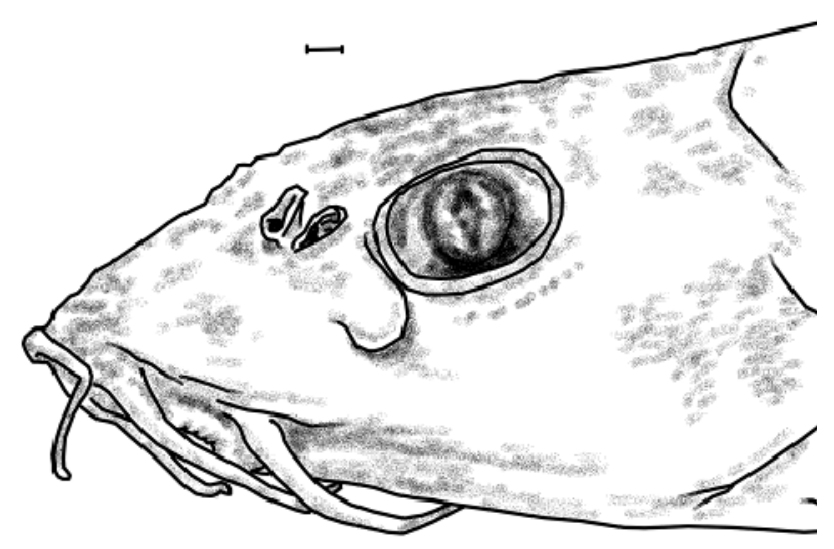

Figure 5: Head of male Physoschistura tuivaiensis showing suborbital flap. Scale bar $=1.0 \mathrm{~mm}$.

Colour in life (Fig. 1C): Body yellowish brown. 12-14 vertically elongated dark olivaceous blotches on flank, originating from lateral line or slightly above, extending ventrally across lower side but not reaching belly. 15-17 dark olivaceous saddles extending from dorsal mid-line to one-third of flank, some of which bifurcate as they reach flank, sometimes alternate and interrupted with blotches forming a sliding appearance with each other anteriorly. Dorsal and dorso-lateral portion of head mottled with irregular dark olivaceous spots. Black caudal bar fragmented into an upper short oblique bar and a lower vertically elongated bar. No black spot present at base of dorsal fin rays but last simple dorsal ray with two black spots of which a large proximal one at one-third distance from base and another smaller distal one at two-thirds distance from base. Two faintly marked black spots on branched dorsal fin rays, of which one at half distance from and another at four-fifths distance from base. Anal and pelvic fins marked with two rows of faint black spots at about half and twothirds of their length from base. Pectoral fin rays dark brown. Caudal fin rays with two rows of pale black spots, forming a V on caudal fin at about half and three-fifths of length from base. Sexes isochromatic.

Colour in preservative: Background colour creamy whitish on body. Spots and blotches light brown. Spots on fins faint brownish.

Distribution: Physoschistura tuivaiensis is known only from two localities in the Tuivai River in the Churchandpur district. The type locality is Likhailok (Fig. 6), but the second locality was not recorded precisely.

\section{Discussion}

Kottelat (1990) revised Physoschistura, with detailed descriptions and illustrations of the five species then known. He was only uncertain about $P$. elongata, the description of which did not conform well with information from the other species. The only addition after 1990 was $P$. yunnaniloides (Chen et al., 2011). Bănărescu \& Nalbant (1995) placed P. raoe in Schistura McClelland, 1838.

Most species of Physoschistura are known only from one or few localities, implying either very restricted distribution or insufficient collection. The majority of the species are found in the Irrawaddy and Salween drainages in Myanmar (Physoschistura brunneana, P. raoe, P. rivulicola, $P$. shanensis, $P$. yunnaniloides), and notably not less than three species are known from Inlé Lake and nearby $\mathrm{He} \mathrm{Ho}$ in the Salween drainage $(P$. brunneana, $P$. rivulicola, $P$. shanensis) (Kottelat, 1990). Physoschistura raoe was described from Mong Yai, on a tributary to the Irrawaddy, but reported also from Mengla by Kottelat (1990). Physoschistura yunnaniloides is known only from Kalaymyo, in the lower Chindwin drainage, and $P$. pseudobrunneana was described from the Mekong and Mae Nam Ping basins.

Physoschistura elongata was described from from the Brahmaputra drainage in Meghalaya. We examined the holotype of $P$. elongata in ZSI/ERS. The specimen is very small and looks like a juvenile. The paratypes are not traceable. The lip structure of the holotype does not conform to that of 
Physoschistura as presented by Kottelat (1990) and Banarescu \& Nalbant (1995). It is more like that of a Schistura. The generic allocation of the species by Sen \& Nalbant (in Singh et al., 1982) is thus doubtful, pending examination of fresh specimens, and we meanwhile tentatively refer it to Schistura. In addition to lip characters, $P$. tuivaiensis differs from $S$. elongata by more simple rays in the anal fin ( 3 vs. 2$)$, more rays in the pelvic fin ( 8 vs. 7$)$, and $8+7$ vs. $8-9+8$ branched caudal fin rays.

The air bladder condition in Physoschistura tuivaiensis conforms to the generic diagnosis (Bănărescu \& Nalbant, 1995; Kottelat, 1990), but the condition has not been verified in all species because too few specimens are available, and a free posterior chamber is not present in $P$. yunnaniloides (Chen et al., 2011).
Physoschistura tuivaiensis, besides having a complete lateral line, differs from congeneric species with incomplete lateral line (P. brunneana, $P$. pseudobrunneana $P$. rivulicola, $P$. raoe) in having fewer branched caudal fin rays $(8+7$ vs. $8-$ $9+8)$ and fewer total pectoral fin rays (10 vs. 11). It is further distinguished from $P$. rivulicola in having 12-14 blotches (vs. 11 bars) on the flanks, 9 (vs. 7) pores in supraorbital and $4+8$ (vs. $4+10$ ) pores in infraorbital canals; from $P$. raoe in having 12-14 blotches (vs. 18 bars) on the flanks, 9 (vs. 6) pores in supraorbital and $4+8$ (vs. 4+11) pores in infraorbital canals; from P. brunneana in having a fewer branched dorsal fin rays $\left(8^{1 / 2}\right.$ vs. $\left.9^{1 / 2}\right)$ and in presence (vs. absence) of well formed axillary pelvic lobe; and from $P$. pseudobrunneana in having 9 (vs. 6) pores in supraorbital canal and in presence (vs. absence) of a shallow median notch in the lower jaw.

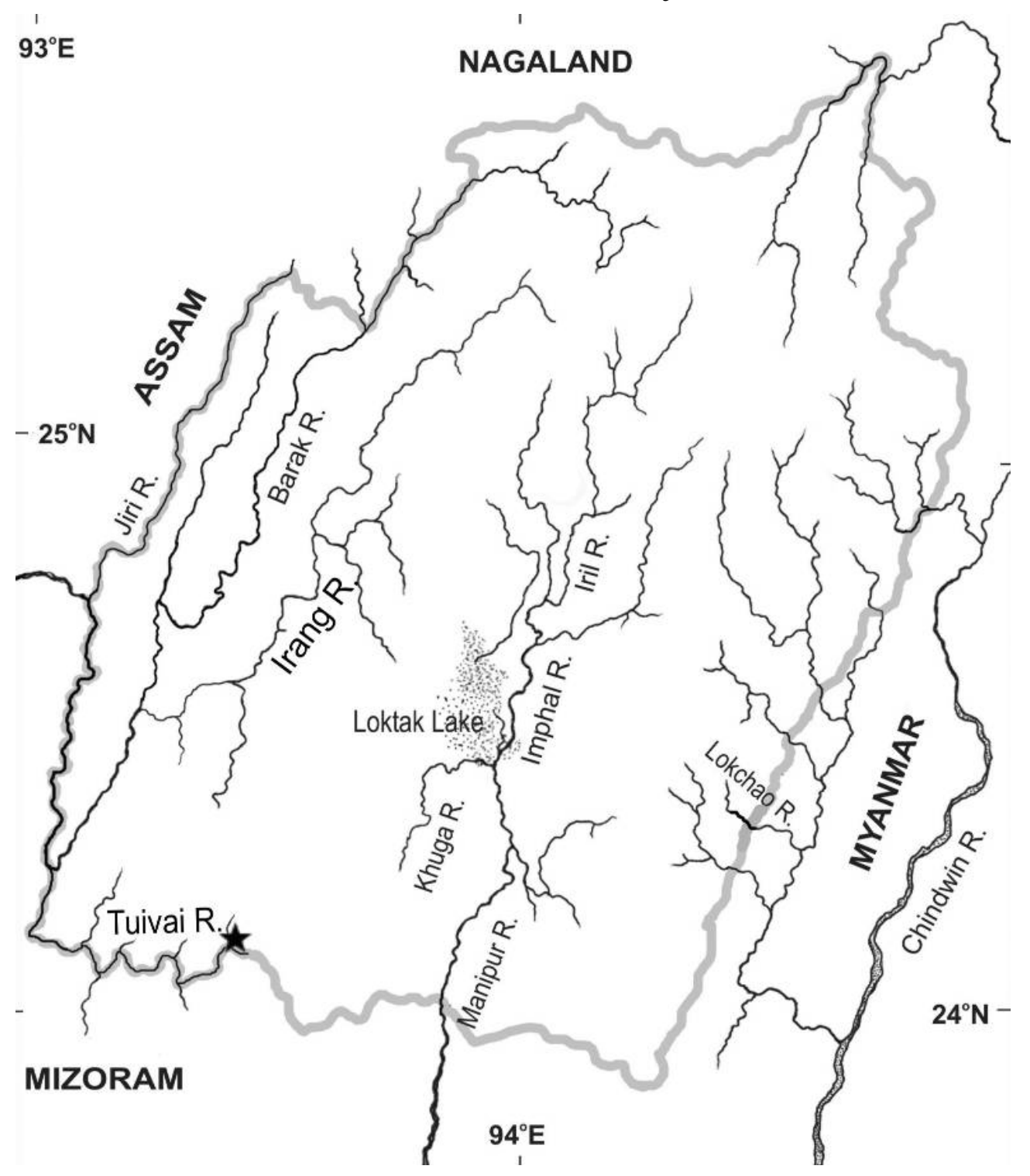

Figure 6: Map of the state of Manipur, showing type locality of Physoschistura tuivaiensis (black star). 


\section{Comparative Materials:}

Physoschistura rivulicola: Holotype, ZSI F11060/1, $48 \mathrm{~mm}$ SL, He-Ho, Shan State, Myanmar (poor state of preservation).

Physoschistura raoe: Holotype, ZSI F11062/1, 28.3 $\mathrm{mm}$ SL, Mong Yai, Shan State, Myanmar.

Physoschistura elongata: Holotype, ZSI V/ERS3063, 29.0 mm SL, Barapani (Brahmaputra Basin), Meghalaya, India.

Published information used for comparison: Kottelat (1990) for Physoschistura brunneana, P. pseudobrunneana and $P$. shanensis, and Chen et al. (2011) for P. yunnaniloides.

\section{Acknowledgements:}

We are very grateful to Amal Krishna Karmakar and Nibedita Sen for permission to examine materials in ZSI, Kolkata and ZSI/ERS, Shillong, respectively. We thank Tan Heok Hui (National University of Singapore) and Remadevi (ZSI) for reviewing the manuscript.

\section{Literature Cited:}

Bănărescu, P. M. and T. T. Nalbant, 1995. A generical classification of Nemacheilinae with description of two new genera (Teleostei: Cypriniformes: Cobitidae). Travaux du Museum d'Histoire Naturelle "Grigore Antipa”, 35: 429-496.

Chen, X-Y., M. Kottelat and D. A. Neely, 2011. Physoschistura yunnaniloides, a new species of loach from Myanmar (Teleostei: Nemacheilidae). Ichthyological Exploration of Freshwaters, 22 (2): 179-183.

Kottelat, M., 1990. Indochinese nemacheilines, A revision of nemacheiline loaches (Pisces: Cypriniformes) of Thailand, Burma, Laos, Cambodia and southern Vietnam. Verlag Dr. Friedrich Pfeil, München: 262.

Singh, A., Sen, N., Bănărescu, P. M. and T. T. Nalbant, 1982. New noemacheiline loaches from India (Pisces, Cobitidae). Travaux du Museum d'Histoire Naturelle“Grigore Antipa”, 23: 201-212.

Vishwanath, W. and K. Shanta. 2004. A new fish species of the Indo-Burmese genus Badis Bleeker (Teleostei: Perciformes) from Manipur, India. Zoos' Print Journal, 19 (9): 1619-1621. 